\title{
Erratum to: The biodiversity of myxomycetes in central Chile
}

\author{
Carlos Lado • Diana Wrigley de Basanta • \\ Arturo Estrada-Torres • Steven L. Stephenson
}

Published online: 3 May 2013

(C) Mushroom Research Foundation 2013

\section{Erratum to: Fungal Diversity}

DOI 10.1007/s13225-012-0159-8

The original publication contains the following errors:

Page 18, second paragraph, line 14: Delete the last sentence ("In the Neotropics, this species has been reported previously from Costa Rica (Rojas et al. 2010) and the Windward Islands."), which should not have been included in this paragraph.

Page 18, fifth paragraph (under Didymium comatum), lines 26-27: Delete "(11-)" from the end of line 26. The sentence should read as "Spores 12-14(-15) $\mu \mathrm{m}$ diam."

The online version of the original article can be found at http://dx.doi.org/ 10.1007/s13225-012-0159-8.

C. Lado $(\bowtie) \cdot$ D. Wrigley de Basanta

Real Jardín Botánico de Madrid, CSIC, Plaza de Murillo, 2,

28014 Madrid, Spain

e-mail: lado@rjb.csic.es

A. Estrada-Torres

Centro de Investigación en Ciencias Biológicas,

Univ. Autónoma de Tlaxcala, Apdo. Postal 183,

Tlaxcala 90000, Mexico

S. L. Stephenson

Department of Biological Sciences,

University of Arkansas, Fayetteville, AR 72701, USA 